\title{
Causes, Symptoms and Treatments Common Hepatitis B Today
}

\author{
Nguyen Tan Danh*
}

\section{Nguyen Tan Danh*}

FPT University, VIETNAM.

\section{Correspondence}

Nguyen Tan Danh

FPT University, VIETNAM

E-mail: nguyentandanh0774@gmail.com

History

- Submission Date: 23-12-2020;

- Review completed: 22-02-2021;

- Accepted Date: 01-03-2021.

DOI : 10.5530/pj.2021.13.82

Article Available online

http://www.phcogj.com/v13/i3

\section{Copyright}

(C) 2021 Phcogj.Com. This is an openaccess article distributed under the term of the Creative Commons Attribution 4.0 International license.

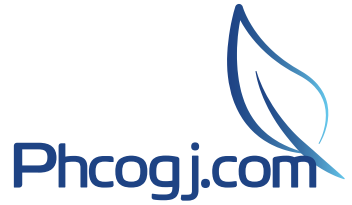

\begin{abstract}
Hepatitis B is the world's most common fatal liver disease caused by the B virus. Vietnam is one of the countries with the highest rates of $B$ virus infection in the world. HBV is transmitted through the blood and body fluids of infected people, just like HIV does, but HBV is nearly 100 times more infectious than HIV. Most hepatitis B infections in adults are fully reversible, even if symptoms are very severe. Although there is currently no effective cure and vaccines that can prevent it, we can still prevent it and cure it if we know how to take some precautions that can avoid infecting others. This article discusses the right solutions for effective treatment and prevention. Some suggestions have been made regarding the scientific composition of herbs, so their application needs more attention.
\end{abstract}

Key words: Hepatitis B, Health, Phyllanthus urinaria, Medication, Prevention.

\section{INTRODUCTION}

In Vietnam, 7.8 million people are living with hepatitis B and nearly one million people are living with hepatitis $C$. This means that one out of nine people in Vietnam is infected with hepatitis $\mathrm{B}$ (HBV) or hepatitis C (HCV) infection. Hepatitis $B$ and C cause nearly 80,000 liver cancer cases and 40,000 deaths each year. One study found that nearly $90 \%$ of people with liver cancer have been or are infected with the hepatitis $B$ and / or C virus. Today, we can prevent and treat this disease. ${ }^{1}$ The hepatitis B vaccine is highly effective when the first dose is given to a baby within 24 hours of birth and three doses thereafter. People with chronic hepatitis $B$ can be treated with highly effective drugs to stop the disease from progressing and reduce the risk of developing liver cancer. People infected with hepatitis $\mathrm{C}$ can now be cured within three months using new oral medications called direct antivirals. ${ }^{2}$ However, many people with hepatitis do not know they are infected and so do not seek treatment. In Vietnam, only about $10 \%$ of people with hepatitis $\mathrm{B}$ and $\mathrm{C}$ are diagnosed and only about $30 \%$ are diagnosed with treatment. ${ }^{3}$

\section{POPULARITY OF HEPATITIS B}

Since people who suffer from liver disease cannot immediately detect the early signs and symptoms of hepatitis B, most of them are in the chronic stage when they start to get sick, therefore, the treatment of hepatitis B also becomes more difficult, the patient needs to take medicines to cure hepatitis $B .{ }^{1}$ Hepatitis B is an infectious disease caused by the $\mathrm{HBV}$ virus, causing infection, inflammation and liver damage, affecting liver function. Acute and chronic hepatitis B is the leading cause of cirrhosis, liver failure, and liver cancer. ${ }^{4}$ The number of people infected with hepatitis B in the world today is about 400 million people (according to WHO statistics). The number of infected people is constantly increasing, Vietnam is one of the countries with a high number of infected people, with about $20 \%$ of the population (Figure 1).

\section{Mechanism of infection}

First is xexually transmission. The HBV virus found in male semen or female vaginal secretions can be transmitted through small cuts during sex. To prevent it, it is necessary to use safety measures, do not have oral sex, indiscriminate sex or use unsanitary tools. ${ }^{5}$

Second is transmission from mother to child. Pregnant women infected with $\mathrm{HBV}$ virus have a very high chance of transmitting to the fetus, up to $90 \%$, if there is no good protection after giving birth, infants and young children would be infected with HBV virus quickly. The likelihood of cirrhosis and chronic hepatitis B in adulthood are very high. ${ }^{2}$

Third is through blood transfusion. Many medical incidents lead to the transmission of HBV virus through blood such as using non-sterile medical equipment, sharing toothbrushes, needles, razors, nail tools, tattoos, etc.

After infection, the incubation period of HBV virus is from 3 to 6 months. Then, the active virus causes acute hepatitis B. If the human body is not autoimmune against the virus, the disease turns to chronic hepatitis $\mathrm{B}$, the patient can only recover and prevent complications.

\section{Stages of hepatitis B}

At acute stage, the patient may have clinical symptoms such as loss of appetite, jaundice, fatigue, nausea, liver pain, dark urine, etc. Abnormal symptoms include elevated bilirubin, especially direct Bilirubin, high liver enzyme index (AST, ALT), HBsAg (+). Chronic stage Patients may have clinical symptoms but often do not manifest as fatigue, weakness, jaundice, jaundice, loss of appetite, loss of appetite, digestive disorders, low-grade fever, pain in the liver, etc. Rather abnormal symptoms include liver enzymes index (AST, ALT) increased continuously or in 6 months, HBsAg (+), visible damage to liver

Cite this article: Danh NT. Causes, Symptoms and Treatments Common Hepatitis B Today. Pharmacog J. 2021;13(3): 644-7. 


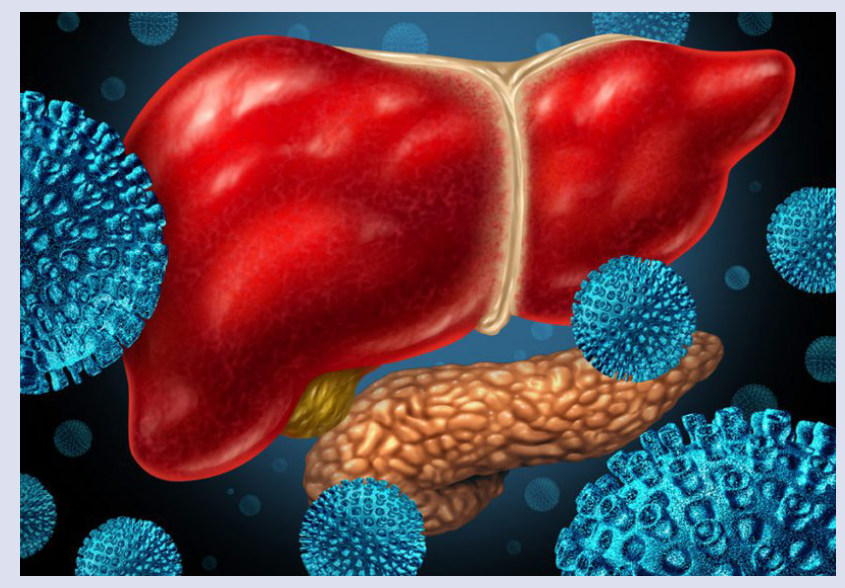

Figure 1: Progression of hepatitis B.

tissue, possibly cirrhosis and cancer liver. ${ }^{6}$

\section{TREATMENT BY MODERN METHODS}

After an incubation period of about 6 months, the hepatitis B virus starts to work and multiplies in numbers. This process disturbs the activity of liver cells, causes chronic hepatitis, cirrhosis, etc.

There are several effective treatments for hepatitis B Currently, medicine has not found a method to eliminate hepatitis B virus completely. ${ }^{7}$ Current treatments only help control and inhibit virus activity, return the virus to a state of inactivity, prevent dysfunction, and restore liver damage. Depending on the medical condition and economic condition, the patient may be treated with the following methods. ${ }^{4}$

Using medication such as Interferon combined with Tenofovir, Lamivudine, and Entercavir is to prevent the intracellular regeneration of the virus. Currently, the cost of treatment with Interferon is quite high, few patients have access. Drugs that reduce patient viral activity require lifelong use. Medicines are still the most common treatment for hepatitis B today. ${ }^{8}$

For the treatment of hepatitis B with western medicine, this method mainly uses antiviral drugs, immunomodulatory agents, and autologous reverse infusion therapy. Also in the method of treating hepatitis B by male medicine, people mainly use herbs in nature. In general, the following measures are used to protect, enhance liver function and detoxify the liver. ${ }^{9}$ The first is an antiviral drug. In the treatment of hepatitis $\mathrm{B}$, the main direction of treatment in western medicine is to use drugs to fight the hepatitis $B$ virus. The main drugs used are those containing $\alpha$ interferon, $\beta$ interferon, $\gamma$ interferon, vidarabi, ribavirin, polyinosinic-polycytidylic acid, etc. The second is immunomodulatory drugs: For the purpose of strengthening the body's immune system to eliminate hepatitis B virus, immunomodulating drugs are also one of the main drugs used to treat hepatitis $B$ in western medicine. ${ }^{10}$ Types that can be used are adrenalin, azathioprin, penicillamin, hydrochlorid, etc. suitable for patients with active chronic hepatitis B with clear autoimmune manifestations, not recommended for patients with chronic hepatitis. Whatever method of treatment for hepatitis $B$, the patient should follow the doctor's instructions to get the best results. At the same time, the improper use of drugs by the patient can also cause many adverse liver effects. Hepatitis B is an early stage disease with unclear signs. Therefore, many patients are often subjective, late detection, causing difficulties in treatment. ${ }^{1}$

Traditional Treatment of hepatitis B can help strengthen and cool the liver, strengthen liver function, then protect the liver without causing side effects. ${ }^{7}$ However, the treatment of hepatitis B with Oriental medicine is still limited, traditional oriental medicine only enhances liver function and it is difficult to eliminate hepatitis B virus from the body. Therefore, many people choose to treat hepatitis B with the combination of oriental medicine and western medication. The combination of hepatitis B treatment with Western medicine, might be one of the best hepatitis B which is rather effective. It is preferred by many people with this disease. Western medicine, to a certain extent, will increase the burden and damage to the liver, therefore, we can combine it with traditional medicine to enhance the detoxifying function of the liver, support the liver to increase efficiency and eliminate the virus faster. ${ }^{11}$

\section{TREATMENT OF PHYLLANTHUS URINARIA}

\section{Scientific composition of phyllanthus urinaria}

This herb grows wild everywhere in Vietnam as well as in parts of the tropics. This wild-growing tree is found mainly in tropical countries such as India, Laos, Indonesia, Taiwan, Nepal, Japan, Thailand, China, Bhutan, South America and Vietnam. Chemical composition includes Flavonoid, phyllanthin alcaloid and hypophyllanthin, niranthin, phylteralin compounds. ${ }^{6}$ In Vietnam, a lot of researches on the treatment effects of phyllanthus urinaria hepatitis have been conducted, such as Hepamarin product from Phyllanthus amarus, Phyllanthin powder (Figure 2).

The effect on the immune system of this herb is quite good. In 1992, Japanese scientists also discovered the effect of inhibiting HIV-1 development from Phyllanthus niruri through the inhibition of HIV replication. In 1996, the Bristol Myezs Squibb Research Institute of Pharmacy also extracted from phyllanthus urinaria an active ingredient with this effect and named it Nuruside. ${ }^{12}$

The second is the detoxifying effect. The Vietnamese, Indian, and Chinese people use phyllanthus urinaria to treat pimples, ulcers, snake bites. According to Malaysian old people, phyllanthus urinaria can be used to treat dermatitis, urinary tract infections, vaginitis, etc. Research works at the Institute of Medicinal Materials - Vietnam (1987-2000) showed that when using a dose of $10-50 \mathrm{~g} / \mathrm{kg}$, phyllanthus urinaria had acute anti-inflammatory effect in mice.

The third is the treatment of gastrointestinal diseases. This medicinal plant has the ability to stimulate appetite (Figure 3). The Indians used to treat hepatitis, jaundice, dysentery, constipation, typhoid, colitis. People in Haiti, Java use this medicinal plant to treat stomach pain, digestive disorders, etc. ${ }^{7}$

Fourth is respiratory disease. The Indians use phyllanthus urinaria to treat cough, bronchitis, bronchial asthma, tuberculosis, etc.

Fifth is analgesic effect. Kenneth Jones and Brazilian researchers have discovered the strong and sustainable analgesic effects of some Phyllanthus species, including Phyllanthus niruri. The analgesic effect of phyllanthus urinaria is 4 times stronger than indomethacin and 3 times stronger than morphine. This effect is demonstrated by the presence of gallic acid, ethyl ester and a mixture of steroids (beta sitosterol and stigmasterol) present in the phyllanthus urinaria. ${ }^{4}$

Next is diabetes treatment. The hypoglycemic effect of phyllanthus urinaria was concluded in 1995, when blood sugar was significantly reduced in diabetics when this drug was given for 10 days.

Each part of this herb contains different chemical ingredients. For example, leaves contain large amounts of bitter active ingredients such as phyllathin and hypophyllanthin. In the body of this herb, there are substances such as Nirtetralin, Niranthin, Flavonoid, Phylteralin, Alcaloid of securinin type such as niruroidin and isobubialin, Lignan, organic acids such as geraniinic, ascorbic acid, repandusinic $\mathrm{A}$ and amariinic acid (Figure 4). 


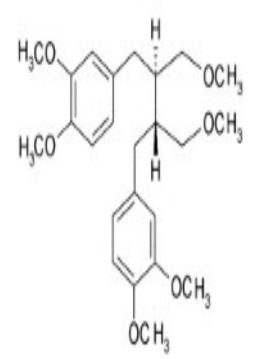

Phyllanthin

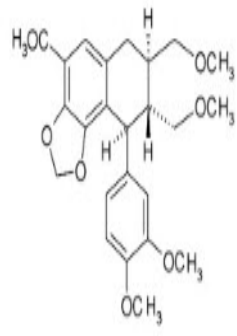

Hypophyllanthin

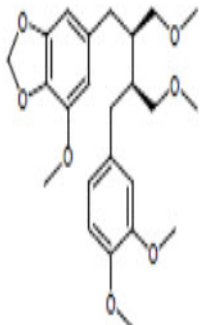

Niranthin
Figure 2: Three main compositions of phyllanthus urinaria.

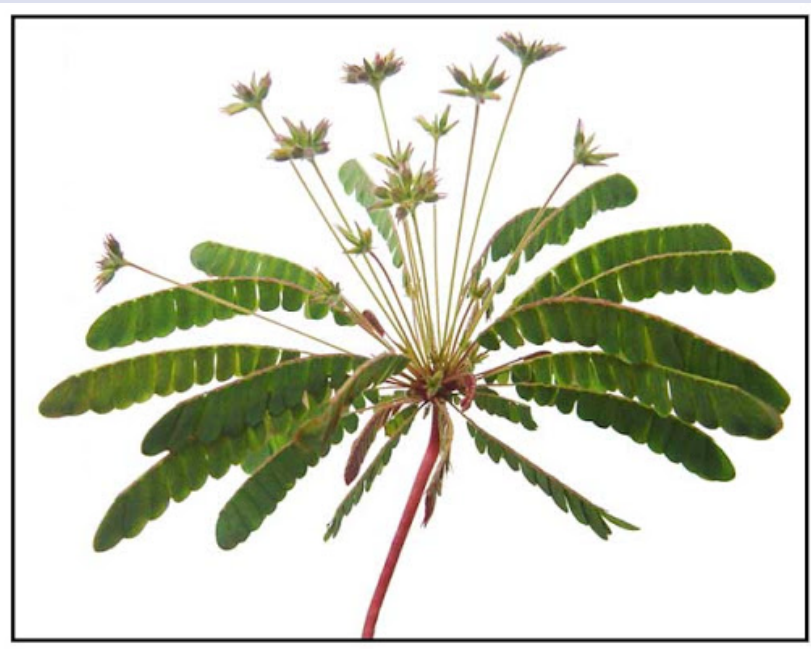

Figure 4: The image of phyllanthus urinary.<smiles>COCC(COC)[C@H](COC)Cc1ccc(OC)c(OC)c1</smiles>

Phyllanthin

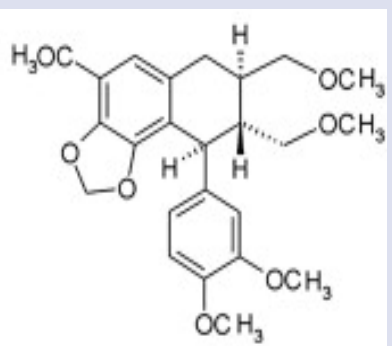

Hypophyllanthin
Figure 4: Two main compositions of phyllanthus urinaria.

Based on research in 1982, Break Stone has shown the anti-hepatitis B virus effect of Phyllanthus niruri. And the 1980 study of India and Japan also determined that the treatment effect of phyllanthus urinaria is thanks to active ingredients contained in this plant such as triacontanal, phyllanthin and hypophyllathin. ${ }^{11}$ Brazilian researchers have shown that the analgesic effects of Phyllanthus niruri 4 times stronger than indomethacin and 3 times morphine, thanks to containing active ingredients such as gallic, mixed steroid (stigmasterol and beta sitosterol) and ethyl ester. Research in 1984 by the University of Pharmacy Santa Catarina - Brazil discovered that the active alkaloid in Phyllanthus niruri helps to treat kidney stones and gallstones. With diuretic properties and treatment of edema, this medicine was used by
Hanoi Traditional Medicine Vietnam in the treatment of cirrhosis of ascites in 1967.

\section{Side effects of phyllanthus urinaria}

Phyllanthus niruri can purify the liver. However, if used in overdose for a long time, it can cause cirrhosis. Phyllanthus niruri does not help with the cure, but makes the condition worse. How to use this medicine is quite simple. Take 100 grams of cooking with water until concentrated and drink with a period of 30-40 days of disease treatment. To eliminate this human disease, hospitals need to invest in hepatitis testing and treatment services. In addition to being the right thing to do for everyone's health, this is a very smart and effective investment as it will save money from much more expensive cancer treatments.

Globally, we are aiming for a $90 \%$ reduction in new hepatitis virus infections and chronic hepatitis deaths. To achieve this goal in Vietnam, hepatitis services must be readily available and affordable for people living with hepatitis B and C. Another important action is to raise awareness about the disease. ${ }^{13}$ Simply put, if people are unaware of hepatitis, they will not take precautions to avoid infection, or will not go for testing and treatment.

Instead, their health will be compromised and they may unintentionally infect others. ${ }^{8}$ In some countries, misunderstanding of hepatitis has resulted in stigma and discrimination against people with it, which also means that people with hepatitis are reluctant to access their treatment. ${ }^{14}$ Lack of awareness of the health effects of hepatitis also means that resources are not being fully allocated to prevent the disease. Let's educate ourselves and others about the risk of viral hepatitis and how to be tested. We can also participate in local advocacy events to raise awareness in the community and show our support in investing more to eradicate the disease. ${ }^{14}$

\section{CONCLUSION}

Early detection and treatment of acute hepatitis B can completely cure the disease. The disease has few obvious symptoms in the early stages, so few patients detect and treat it. Testing for hepatitis B in people at high risk who have symptoms is the earliest way to detect the disease. There are also many effective traditional herbal remedies in the treatment of chronic hepatitis B. However, the remedy only helps restore liver function, reduce damage and activity of the virus. Patients still need initial treatment with more aggressive drugs or methods. Phyllanthus niruri brings many good effects to health. However, the patient should not overdo it, to avoid the case of drugs causing side effects affecting health.

\section{ACKNOWLEDGMENTS}

The author would like to send my sincere thanks to those who gave me great advice to complete the research paper.

\section{CONFLICTS OF INTEREST}

None.

\section{ETHICAL CLEARANCE}

The author ensures the quality and integrity of my research. The ideas and opinions expressed in this paper are my effort.

\section{REFERENCES}

1. Huang, S. T., Pang, J. H. S., \& Yang, R. C. Anti-cancer effects of Phyllanthus urinaria and relevant mechanisms. Chang Gung Med J. 2010; 33:477-87.

2. Wahyuni, T. S., Permanasari, A. A., Widyawaruyanti, A., Hotta, H., AokiUtsubo, C., \& Hafid, A. F. Antiviral Activity of Indonesian Medicinal Plants against Hepatitis B Virus. Pharmacognosy Journal. 2020;12. 
3. Huang, S. T., Yang, R. C., Yang, L. J., Lee, P. N., \& Pang, J. H. S. Phyllanthus urinaria triggers the apoptosis and $\mathrm{Bcl}-2$ down-regulation in Lewis lung carcinoma cells. Life Sciences. 2003;72:1705-16.

4. Rehermann, B., \& Nascimbeni, M. Immunology of hepatitis B virus and hepatitis C virus infection. Nature Reviews Immunology. 2005; 5:215-29

5. Terrault, N. A., Lok, A. S., McMahon, B. J., Chang, K. M., Hwang, J. P., Jonas, M. M., ... \& Wong, J. B. Update on prevention, diagnosis, and treatment of chronic hepatitis B: AASLD 2018 hepatitis B guidance. Hepatology. 2018; 67:1560-99.

6. Mathew, S., Faheem, M., Suhail, M., Fatima, K., Archunan, G., Begum, N., ... \& Qadri, I. Updates on Traditional Medicinal Plants for Hepatocellular Carcinoma. Pharmaceutical Journals. 2016;8.

7. Hoi, H. T. Great Effect of Fallopia Multiflora and Other Herbs in Poliosis Treatment. Pharmacognosy Journal. 2020;12:1600-4.

8. Kao, J. H., Chen, P. J., Lai, M.Y., \& Chen, D. S. Hepatitis B genotypes correlate with clinical outcomes in patients with chronic hepatitis $B$. Gastroenterology. 2000; 118:554-9.
9. Van Anh, T. N., Le, T. V., Van Bui, M., Pham, T. Q., Do, B. N., \& Nguyen, L. H. T. Tacrolimus Therapeutic Drug Monitoring in Vietnamese Renal Transplant Recipients. Pharmacognosy Journal. 2020;12.

10. Dienstag, J. L. Hepatitis B virus infection. New England Journal of Medicine. 2008;359:1486-500.

11. Liang, T. J. Hepatitis B: the virus and disease. Hepatology. 2009;49:S13-21.

12. Borgia, G., Carleo, M. A., Gaeta, G. B., \& Gentile, I. Hepatitis B in pregnancy. World journal of gastroenterology: WJG. 2012; 18:4677.

13. Shepard, C. W., Simard, E. P., Finelli, L., Fiore, A. E., \& Bell, B. P. Hepatitis B virus infection: epidemiology and vaccination. Epidemiologic reviews. 2006;28:112-25.

14. Quang, M. N., Tan, H. H., \& Hoang, C. V. Some Effective Ways for Treating Flu. In Proceedings of the 2019 2nd International Conference on Electronics and Electrical Engineering Technology. 2019:123-6.

\section{GRAPHICAL ABSTRACT}

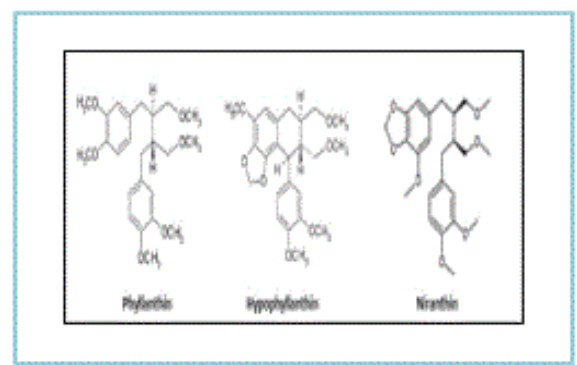

Three main compositions of phvllanthus

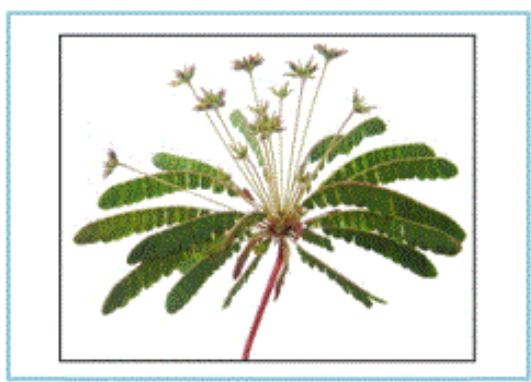

The image of phyllanthus

\section{HEPATITIS B}

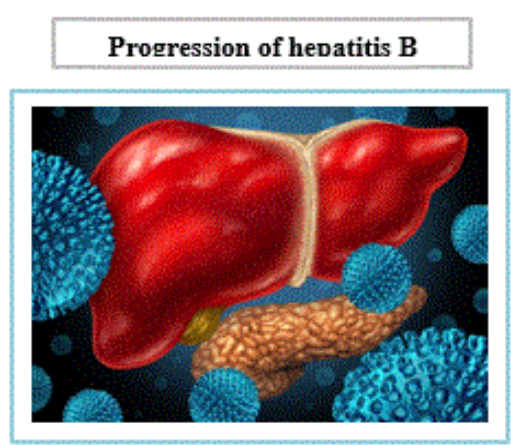

\section{ABOUT AUTHOR}

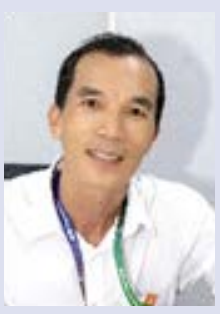

The author is now a lecturer of FPT University. His majors are IT, education, environment and medication. His some recent publications:

1) Danh, N. T. (2020). Benefits of exploiting wind power at sea in Vietnam. In E3SWeb of Conferences (Vol 211, p. 03002). EDP Sciences.

2) Danh, N. T. (2020). Some benefits of improving urban air quality from the perspective of Ho Chi Minh City people. In E3S Web of Conferences (Vol. 211, p. 01005). EDP Sciences. 